\title{
PROFESSOR WERNER FRIEDLI
}

A VERY brief illness terminated most prematurely the career of this brilliant young Swiss on 14 September I936. Born on 26 September 1893 at Mühledorf, he was always delicate in consequence of an unlucky fall in infancy. This in no wise impaired his mental powers or social gifts, both remarkably developed, whereby he gained a wide circle of friends and admirers.

The decisive factor in his career was that he came under the influence of the late Prof. Moser who taught and helped him. Later Friedli obtained a post in the Federal State Insurance Bureau, where he assisted with many of the difficult problems that arose. In 1924 he became actuary to the Insurance Fund for the Federal Officials, Employees and Workmen, devoting himself thereafter to the study of Social Insurance. $\mathrm{He}$ was entrusted with the preparation of pioneer work for the contemplated Swiss National Health Insurance Bill, the subsequent overthrow of which was a bitter disappointment. His heavy labours in this field by no means limited his activities in other directions, and the bare list of his publications given in the Swiss Bulletin (from which these particulars are abstracted) makes a strong impression of great ability and untiring energy. It is thus not surprising that, on Prof. Moser's retirement in I93I from the Actuarial Seminary, he should have been selected to succeed his beloved master. It is sad that he has not been spared longer to the further advantage of his profession and his country.

G. W. R. 